\title{
ENERGY EFFICIENCY RETROFITTING OF LIGHTING IN UNIVERSITY LIBRARIES BASED ON ILLUMINATION SUITABILITY ANALYSIS
}

\author{
Bojun WANG ${ }^{1,2}$, Xiaojun $\mathrm{LIU}^{1 *}$, and Yanping YANG ${ }^{1,2}$ \\ ${ }^{1}$ School of Management, Xi'an University of Architecture \& Technology, Xi'an, China; \\ ${ }^{2}$ College of Zhangjiagang, Jangsu University of Science \& Technology, Suzhou, China; \\ *E-mail:wbj7266996@163.com
}

\begin{abstract}
Taking the lighting energy efficiency retrofitting of a university library as a case study, this study aims to solve the existing problems in energy efficiency retrofitting in library lighting, such as one-sided consideration of factors, deviation from reality, and rebound of energy use. On the basis of illuminance suitability analysis, this study considers the technology and economy factors into the decision-making process and constructs a decision-making system for realizing the energy saving goal of the system. Findings show that using the illuminance suitability analysis data to determine the illuminance trigger threshold of energy saving light source and intelligent lighting system can guarantee the lighting energy saving rate and lighting visual environment, eliminate the "energy use rebound effect", and achieve good technical and economic results.
\end{abstract}

Keywords: intelligent lighting, energy efficiency retrofitting, illuminance analysis, economic evaluation

\section{INTRODUCTION}

Building energy consumption accounts for approximately $40 \%$ of total energy consumption, which makes the building the main target of energy efficiency retrofitting [1]. A primary means to reduce building energy consumption is energy efficiency retrofitting of existing buildings, the important part of which is the lighting ener- gy efficiency retrofitting. The measured data from Tsinghua University show that lighting power consumption accounts for (20-40)\% of the total energy consumption of large public buildings [2]. Swedish researchers found that the actual average annual energy consumption of lighting systems in office buildings was $21 \mathrm{~kW} \cdot \mathrm{h} / \mathrm{m}^{2}$, whereas theoretical calculations and simulation experiments showed that the annual average energy consumption of lighting systems reached $10 \mathrm{~kW} \cdot \mathrm{h} / \mathrm{m}^{2}$, which could satisfy the demand for office lighting, and the energy saving space was $50 \%$ [3]. Particularly, the lighting energy consumption in a university library is higher than that of common public buildings, and reducing the lighting energy consumption of a university library has obvious effect on building energy saving.

Many buildings only consider lowering the lighting power but neglect the change of illuminance value after retrofitting due to the lack of systematic consideration. Other studies have shown that users tend to exert minimal effort on energy saving and have an "energy use rebound" effect after energy efficiency retrofitting due to the reduction of energy consumption [4], which results in a decline in the effectiveness of energy efficiency retrofitting. Meanwhile, some schemes of lighting energy efficiency retrofitting only focus on the high standard of lighting system but ignore the economic feasibility, which results in the failure of the energy efficiency retrofitting.

According to the above analysis, this study takes a university library as an example to optimize the 
process of lighting energy efficiency retrofitting completely and achieve its overall goal

\section{RELATED WORKS}

Scholars at home and abroad have studied lighting energy conservation from theory and practice. In the development of lighting energy saving technology, some scholars have attempted to apply outdoor intelligent lighting control systems to green and intelligent buildings [5], use energy saving control sensors in changing the brightness of luminaires [6] and lighting system composed of multiple control devices [7], and apply remote traffic engineering modelling technology to lighting control systems [8].

In terms of illumination analysis, using intelligent management system can maintain maximum visual comfort [9]; using energy saving glass to reduce reflection and astigmatism can save lighting energy consumption [10]; utilizing a hyperbolic lens can improve the uniformity of the illumination of light emitting diode (LED) light source [11]; and using of daylight reasonably can improve visual comfort [12].

In view of the energy use rebound effect, the design and test of ecological feedback system, simulation of lighting consumption [13] and lighting feedback [14], deployment of new energy monitoring system, and investigation of new energy use behaviours [15] can adjust human energy use behaviour and improve lighting system for reducing energy consumption.

From the existing literature, most scholars at home and abroad lack a systematic and comprehensive perspective by focusing on certain type of technology or a certain phenomenon to study the unilateral problems of lighting energy saving. However, the actual lighting energy efficiency retrofitting is a comprehensive system engineering that integrates technology, economy, and management. Moreover, the lack of analysis of key elements brings risks to project implementation. Therefore, this study comprehensively considers all elements of lighting energy efficiency retrofitting of university libraries and their relations starting from the engineering practice and formulates practical and feasible retrofit schemes to address the shortcomings of previous studies.

\section{DESIGN OF ENERGY SAVING SCHEME FOR LIGHTING}

\subsection{Research Ideas}

The present work adopts the research method for combining practical test with theoretical analysis to design and verify the scheme of lighting energy efficiency retrofitting of a university library. First, an irradiance test is conducted to ensure that the illuminance of energy saving lamps after retrofitting is not lower than the original illumination level, and the amount of energy saving produced by luminaires replacement is analyzed. Second, the intelligent lighting system suitable for the university library is replaced by manual management to overcome the energy use rebound effect while improving energy efficiency. Finally, the economic benefits of lighting energy efficiency retrofitting are verified by calculating the dynamic investment payback period.

\subsection{Analysis of Illuminance Suitability}

This study aims to solve the current problem that the lighting energy efficiency retrofitting only pays attention to the change of lighting power and neglects the illumination suitability by analyzing the illuminance and power of energy saving luminaire via field test. The luminaire is selected as the light source after energy efficiency retrofitting to satisfy the requirements of illuminance and amount of energy saving.

The analysis shows that the reading room and the stacks have the largest lighting area, and the reading room has the highest requirements for the illumination comfort. Therefore, this experiment selects the reading room to perform the illuminance test and analyzes the energy saving of changing the lighting equipment under the same illuminance. The uniformity ratio of the illuminance is then analyzed, and the fitting degree between the measured and theoretical illuminance is compared to correct the value of correlation coefficient in the illumination theory formula (1) as the basis for related calculations.

In theory, indoor illuminance is usually used as the evaluation index of illuminance suitability. On the basis of "utilization coefficient method" for indoor illumination analysis, the theoretical calcu- 


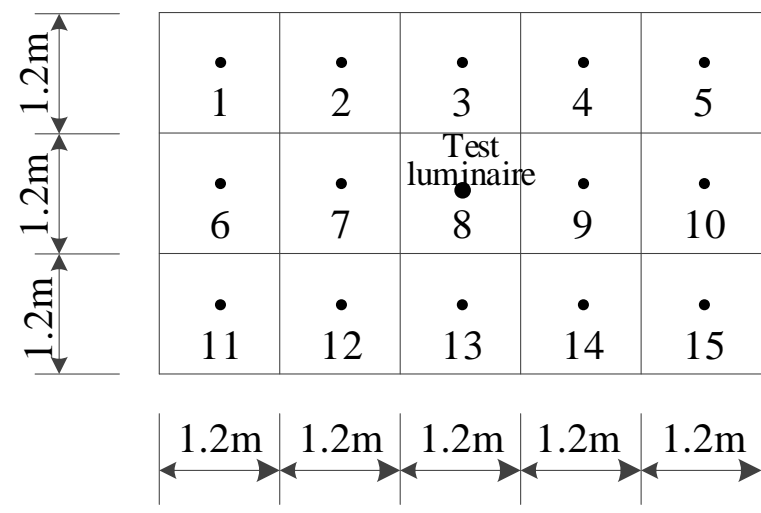

Fig. 1. Scheme of test points

lation formula for the illuminance of the test point on the working surface is as follows:

$$
E_{t i}=\frac{(\phi \times U \times M)}{A},
$$

where $E_{t i}$ is the theoretical calculation value of the illumination of the test point $i$ on the test face [lx], $\phi$ is the luminous flux parameter of luminaire itself [ $[\mathrm{m}], U$ is the utilization factor, $M$ is the maintenance factor, and $A$ is the area of the illuminated surface in the room.

Formula (1) indicates that when the illuminance test is conducted, the influences of the parameters of the luminaire itself and the room environment factors on the indoor illuminance should be considered.

According to the testing requirements of illuminance in "Measurement methods for lighting" (GB/T 5700-2008), the central point method is used in this experiment to design the testing environment and arrange the measuring points. The field average illuminance measured by the centre point method is calculated as

$$
E_{a v}=\frac{\sum E_{i}^{a}}{M \times N},
$$

where $E_{a v}$ is the average illuminance on the test surface [lx], $E_{i}^{a}$ is the measured illuminance of point $i$ on the test surface [lx], $M$ is the vertical number of distribution points, and $N$ is the horizontal number of distribution points.

In the experiment, an illumination test platform with three horizontal and five vertical squares is constructed, and the test points are established at the centre of each square, as shown in Fig. 1. The distance between measured points is $1.2 \mathrm{~m}$ longitudinally and laterally; the height of the test face from the ground is $0.75 \mathrm{~m}$; and the distance from the luminaires to the test face is $2.05 \mathrm{~m}$. TES-1339 illuminance meter is used, and the test time selected is after 22:00 when the room is unaffected by other light sources.

All six types of lamp being used and the five types of LED lamp as alternative light sources are selected for grouping comparison test to select the new light source on the basis of the illumination suitability and energy saving rate. The luminaire numbers, grouping, test comparison parameters, and replacement results are shown in Table 1.

Table 1 indicates that when the illumination requirements are satisfied, the LED series luminaires that replace the original luminaires as the energy-saving light source can save energy remarkably.

The test results are the average value of illuminance of every single lamp in each point, and the uniformity ratio of illuminance of the test platform is reflected by the actual illumination distribution of each measuring point. The actual test data of T8 LED are considered as the representative, formula (1) is used for the theoretical calculation and simulation, and the actual and calculated illuminance and their distribution of each T8 LED measured point are obtained (Fig. 2(a)). In addition, whether the entire illumination value, uniformity ratio of illuminance, and lighting power density (LPD) of the room with energy saving luminaires meet the requirements must be tested and identified. Taking the first reading room as an example, the overall illumination and LPD of the room before and after the retrofitting are compared. Theoretical calculations show that if the reading room's lamp positions and its number remain unchanged, and each lamp position is replaced by three T8 LED tubes in parallel installations, then the reading room will be equipped with 116 sets of lamps, and the power of each set of lamps is $56 \mathrm{~W}$. Hence, the requirements for illuminance and power density of the reading room can be completely satisfied, and the construction cost can be avoided by changing the lamps power and quantity. To verify whether the relevant indexes after lighting energy efficiency retrofitting satisfy the design requirements, the test platform is arranged, as shown in Fig. 2. Table 2 presents the related parameters and test, and Fig. 2(b) shows the calculated and measured values of the entire illuminance of the reconstructed room.

Table 2 shows that the power of three T8 fluorescent tubes in parallel installations and electro- 
Table 1. Illuminance Test and Replacement Result of Luminaires

\begin{tabular}{|c|c|c|c|c|c|c|}
\hline NO. & Luminaire Model & $\begin{array}{l}\text { Power, } \\
\text { W }\end{array}$ & $\begin{array}{l}\text { Luminous } \\
\text { flux, } \mathbf{l m}\end{array}$ & $\begin{array}{c}\text { Average } \\
\text { illuminance, } 1 x\end{array}$ & $\begin{array}{l}\text { Replacement } \\
\text { result }\end{array}$ & $\begin{array}{l}\text { Energy saving } \\
\text { rate, \% }\end{array}$ \\
\hline 1 & T5Fluorescent lamp & 28 & 1720 & 49.6 & T5 LED & 46 \\
\hline 2 & T5 LED & 15 & 1860 & 53.9 & & \\
\hline 3 & T8Fluorescent lamp & 36 & 1800 & 52.3 & T8 LED & 50 \\
\hline 4 & T8 LED & 18 & 2070 & 60.7 & & \\
\hline 5 & $\begin{array}{l}\text { 3U Energy saving } \\
\text { lamp }\end{array}$ & 20 & 1260 & 37.8 & 11W LED bulb & 45 \\
\hline 6 & $\begin{array}{l}\text { 3U Energy saving } \\
\text { lamp }\end{array}$ & 14 & 730 & 21.1 & 6W LED bulb & 57 \\
\hline 7 & $\begin{array}{l}\text { Spiral energy saving } \\
\text { lamp }\end{array}$ & 13 & 670 & 19.7 & 6W LED bulb & 54 \\
\hline 8 & $\begin{array}{c}\text { Spiral energy saving } \\
\text { lamp }\end{array}$ & 6 & 346 & 10.9 & 4W LED bulb & 33 \\
\hline 9 & LED bulb & 11 & 1070 & 42.2 & & \\
\hline 10 & LED bulb & 6 & 590 & 22.4 & & \\
\hline 11 & LED bulb & 4 & 430 & 13.6 & & \\
\hline
\end{tabular}

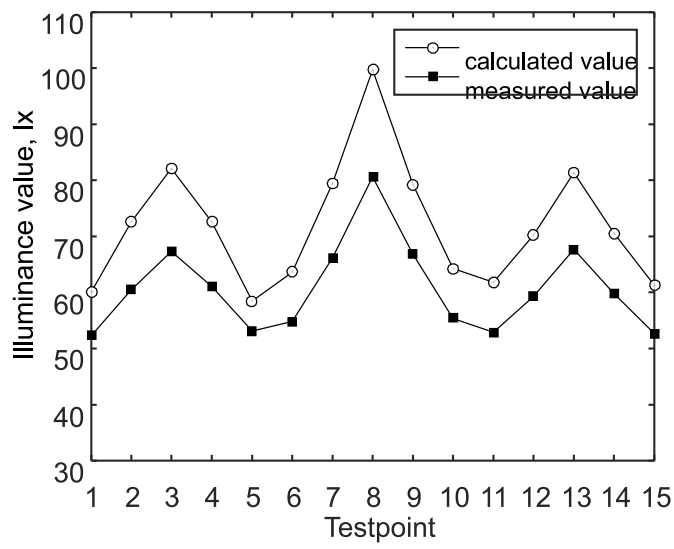

(a) T8 LED illumination distribution

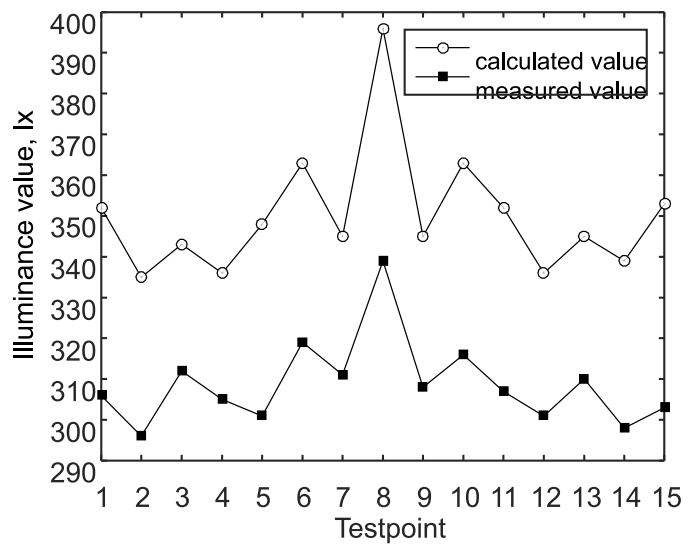

(b) Distribution of overall illumination after reformation

Fig. 2. Calculated and actual values of illuminance and its distribution

nic ballast used before retrofitting is $120 \mathrm{~W}$ per set. Although the illuminance conforms to the standard, the LDP value exceeds it. After replacing three T8 LED tubes in parallel installations, each index is better than the target value.

The distribution trend of the two types of test data and the calculated results at each measuring point are consistent (Fig. 2), which verifies the correctness of formula (1). The overall calculation result is slightly higher than the measured value because of the high value of the utilization coefficient $U$ and the maintenance coefficient $M$, such that the empirical values of $U$ and $M$ must be revised according to the actual situation.

\subsection{Design of Intelligent Lighting}

Illumination testing is an important link in the implementation of lighting energy efficiency retrofitting. However, automatic control of lighting system, that is, intelligent lighting must be implemented to achieve the goal of lighting energy efficiency retrofitting. First, the traditional manual control lighting system not only increases the cost of labour 
Table 2. Uniformity Ratio of Illuminance and LPD Analysis

\begin{tabular}{|c|c|c|c|c|c|c|c|}
\hline \multirow{2}{*}{$\begin{array}{l}\text { Light Source } \\
\text { Model }\end{array}$} & \multirow{2}{*}{$\begin{array}{c}\text { Combination } \\
\text { mode of } \\
\text { luminaires }\end{array}$} & \multirow{2}{*}{$\begin{array}{c}\text { Power } \\
\text { per set, } \\
\text { W }\end{array}$} & \multirow{2}{*}{$\begin{array}{l}\text { Luminous flux } \\
\text { per set, } \mathbf{I m}\end{array}$} & \multicolumn{2}{|c|}{ Illuminance, $\mathbf{l x}$} & \multicolumn{2}{|c|}{$\mathrm{LDP}, \mathrm{W} / \mathrm{m}^{2}$} \\
\hline & & & & $\begin{array}{c}\text { target } \\
\text { value }\end{array}$ & $\begin{array}{c}\text { measured } \\
\text { value }\end{array}$ & $\begin{array}{l}\text { target } \\
\text { value }\end{array}$ & $\begin{array}{c}\text { measured } \\
\text { value }\end{array}$ \\
\hline $\begin{array}{l}\text { T8 fluorescent } \\
\text { lamp }\end{array}$ & $\begin{array}{c}3 \text { lamps in } \\
\text { parallel }\end{array}$ & 120 & 6210 & 300 & 283.2 & 9 & 16.98 \\
\hline T8 LED & $\begin{array}{c}3 \text { lamps in } \\
\text { parallel }\end{array}$ & 56 & 5400 & 300 & 308.8 & 8 & 7.91 \\
\hline
\end{tabular}

but also loses control of the opening of light source according to the actual demand of each room, thereby wasting considerable electric energy. Second, people tend to desalinate the consciousness of energy saving and the phenomenon of energy use rebound becomes evident because of the decrease of lighting power. However, the manual control lighting system cannot overcome this phenomenon. Finally, manual control can neither effectively identify the effect of outdoor natural light on illuminance nor fully use natural light to reduce lighting energy consumption.

The analysis of the electricity utilization data of each room before the lighting energy efficiency retrofitting of the library indicates that the stacks and the reading room have large lighting area, dense light source, and high demand for illuminance, accounting for over $85 \%$ of the total lighting power consumption of the library, which is the key point of lighting energy saving control. Therefore, the intelligent lighting control system, which is designed for the stacks and the reading room, provides three control modes or their combination, that is, timing, inductive, and illuminance control. Inductive control is adopted for the other public rooms or passageways. The stacks adopt the combined mode of timing and inductive. During opening hours, only the luminaires of the main channels are opened. The bookshelf and reading areas are equipped with dual technology detector to sense the activity of the personnel. The lighting system in the area is automatically turned on when someone looks up for books and periodicals, and the lighting system automatically shuts down otherwise. The reading room adopts the illuminance control preferentially, supplemented by the induction control mode. During regular opening hours of the reading room, the brightness of the artificial light source is reduced automatically when the illuminance is higher than the set value. Correspondingly, the induction con- trol mode is activated when the illuminance is below the set value and automatically turns on the lighting for people's reading activities. The illumination detection of the reading area near the outer window is strengthened to maximize the use of natural light, obtain comfortable visual environment, and save electricity for lighting. Generally, the closer the reading area is to the window, the higher the illuminance of the natural light and the weaker the artificial illumination. By adjusting the illuminance of artificial light source through intelligent control system, the synthetic illuminance can be maintained within the set range.

The management platform of the intelligent lighting system is designed according to the network control mode, and the lighting trigger threshold is set simultaneously with the illuminance test. The trigger threshold of the dual technology detector is set according to the sensitivity requirement. Intelligent meter is set up in each lighting control area to realize acquisition, statistics, and transmission of energy consumption data. The intelligent lighting controller in the system has the function of conventional/intelligent mode switching, which can automatically switch to normal mode in case of network failure and improve the reliability of the system. Fig. 3 shows the structure of the intelligent lighting system.

To test the energy saving effect of the intelligent lighting system, the intelligent lighting system is divided according to the floor and kept running according to the conventional control mode and the intelligent lighting mode for one week after completing the retrofitting and the trial operation of the intelligent lighting system. The opening time of luminaires per day, the average rate of lights off, and the amount of electricity consumed are recorded, and the data obtained are compared with those obtained before lighting energy efficiency retrofitting. Table 3 shows the test results. 


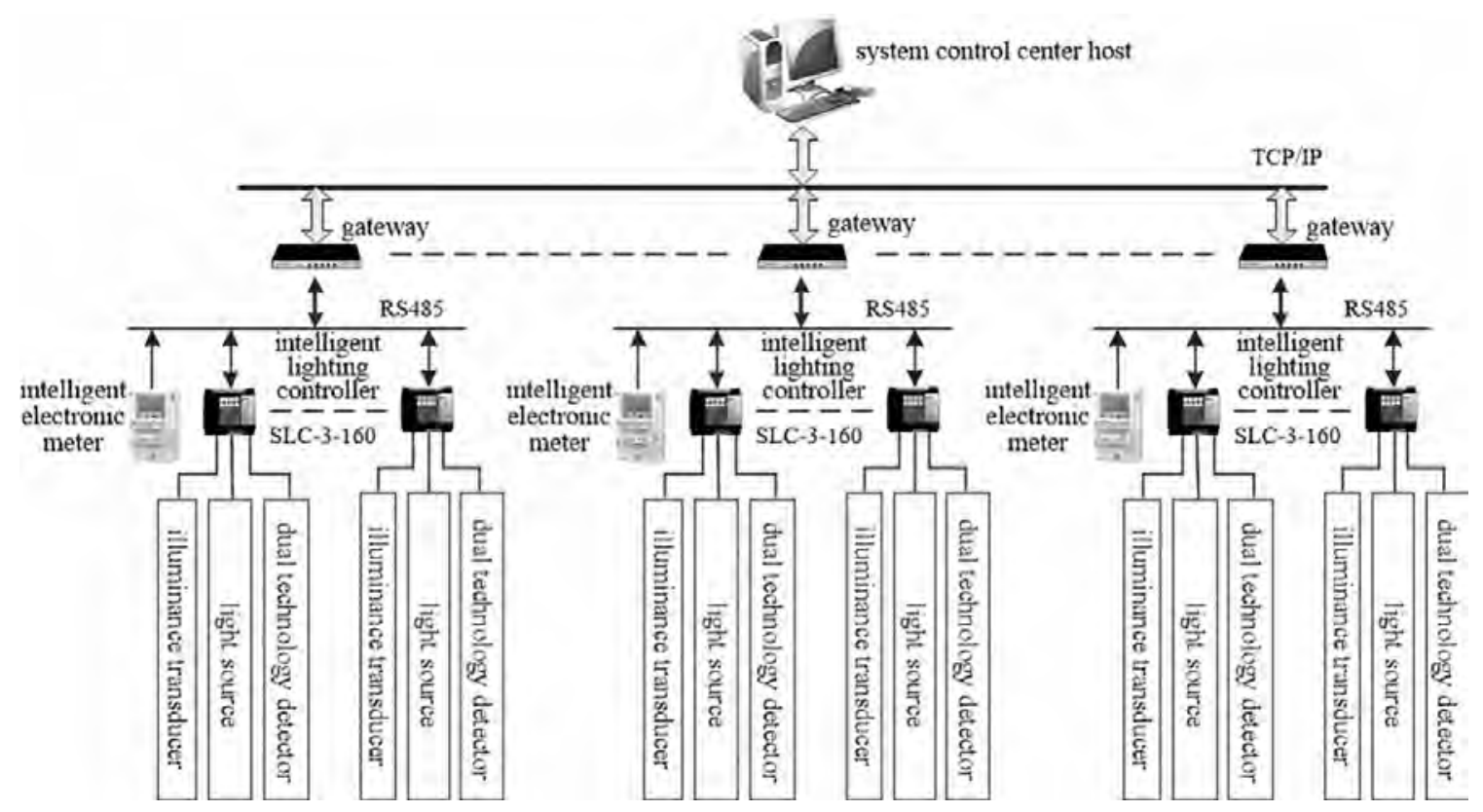

Fig. 3. Structural diagram of the intelligent lighting system

Table 3 shows that the total electricity consumption of the intelligent mode for one week after retrofitting is 49.61 less than that before retrofitting. If the conventional mode is adopted, then it is only $28.47 \%$ less than before retrofitting. The opening time of luminaires after retrofitting evidently increases, whereas the ratio of lights off decreases. This result is the main reason for the significant increase in energy consumption of the intelligent mode and is a typical phenomenon of energy use rebound.

\subsection{Economic Effect Evaluation}

On the basis of the energy consumption bill of three consecutive years before lighting energy efficiency retrofitting of the library, the average annual lighting power consumption is $545,569.65 \mathrm{~kW} \cdot \mathrm{h}$ after the lighting energy efficiency retrofitting and the average weekly electricity consumption is $5,288.32$ $\mathrm{kW} \cdot \mathrm{h}$ under intelligent mode for 36 weeks. With the library being open for 48 weeks a year, the annual saving power consumption is $291,730.29 \mathrm{~kW} \cdot \mathrm{h}$. If the average electricity price is 0.89 yuan, then 259,640 yuan will be saved every year. Given the long service life and low failure rate of replaced LED lamps, maintenance cost can be saved. In addition, the use of intelligent lighting system can save on labour management fees and increase the operation and maintenance costs of intelligent system. Table 4 shows the costs details.
The planned payback period is 3.5 years. Given the opportunity cost of investment and the average social return rate, the dynamic investment payback period is calculated as

$$
C_{E}=\frac{\left.B[i 1+i)^{n}\right]}{(1+i)^{n}-1},
$$

where $C_{E}$ is the total investment; $B$ is the total revenue; $i$ is the social benchmark rate of return, which is assumed to be $8 \%$; and $N$ is the dynamic investment payback period. After introducing $C_{E}=776,573, B=364,520$, and $i=8 \%$ into formula (3), $n$ (2.44 years) is less than 3.5 years, and the investment returns are significant.

\section{RESULT ANALYSIS AND DISCUSSION}

According to the functional characteristics of the rooms on each floor of the library, the lighting energy efficiency retrofitting system is established based on illumination suitability analysis, and the intelligent lighting system is used to control the system. The overall energy savings rate reaches $50 \%$, the dynamic investment payback period is 2.44 years, and the effect of energy efficiency retrofitting is good.

The project is based on the illuminance test data to design the retrofit scheme. Through the illumination test, the performance of the energy sa- 
Table 3. Experimental Data of Lighting Energy Consumption for One Week in Different Control Modes

\begin{tabular}{|c|c|c|c|c|c|c|c|c|c|}
\hline \multirow[b]{2}{*}{$\frac{\grave{a}}{\bar{I}}$} & \multicolumn{3}{|c|}{$\begin{array}{l}\text { Conventional mode before } \\
\text { retrofitting }\end{array}$} & \multicolumn{3}{|c|}{ Intelligent mode after retrofitting } & \multicolumn{3}{|c|}{$\begin{array}{l}\text { Conventional mode after } \\
\text { retrofitting }\end{array}$} \\
\hline & 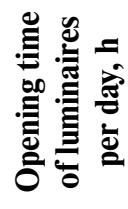 & 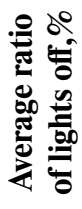 & 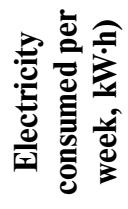 & 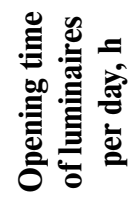 & 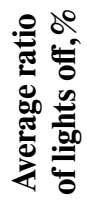 & 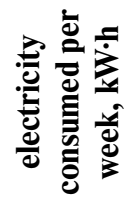 & 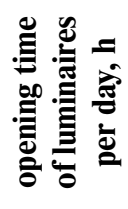 & 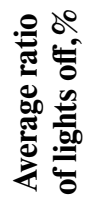 & 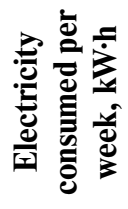 \\
\hline $5 \mathrm{~F}$ & 8 & 11 & 836.32 & 6 & 33 & 425.68 & 10 & 6 & 585.36 \\
\hline $4 \mathrm{~F}$ & 13 & 13 & 2657.76 & 11 & 35 & 1372.29 & 15 & 8 & 1964.44 \\
\hline $3 F$ & 14 & 12 & 2825.56 & 11.5 & 29 & 1413.75 & 16 & 7 & 1958.47 \\
\hline $2 \mathrm{~F}$ & 14 & 11 & 3019.17 & 12 & 26.5 & 1516.13 & 16 & 7.5 & 2152.92 \\
\hline $1 \mathrm{~F}$ & 11 & 10 & 1358.86 & 9 & 31 & 662.83 & 13.5 & 9 & 989.76 \\
\hline
\end{tabular}

Table 4 Cost Benefit Details of Lighting Energy Efficiency Retrofitting (Yuan/Year)

\begin{tabular}{|c|c|c|c|c|c|c|}
\hline Cost name & $\begin{array}{c}\text { Total } \\
\text { investment } \\
\text { (CE) }\end{array}$ & $\begin{array}{c}\text { Save } \\
\text { electricity }\end{array}$ & $\begin{array}{c}\text { Save } \\
\text { labour } \\
\text { costs }\end{array}$ & $\begin{array}{c}\text { Save } \\
\text { maintenance } \\
\text { expenses }\end{array}$ & $\begin{array}{c}\text { Maintenance } \\
\text { expenses of the } \\
\text { intelligent system }\end{array}$ & $\begin{array}{c}\text { Total } \\
\text { revenue } \\
\text { (B) }\end{array}$ \\
\hline $\begin{array}{c}\text { amount of } \\
\text { money }\end{array}$ & 776573 & 259640 & 76560 & 65200 & 36880 & 364520 \\
\hline
\end{tabular}

ving lamps, the overall illumination uniformity ratio, and power density of the room are guaranteed. In the intelligent lighting system with illuminance priority, the setting and modification of the illuminance sensor trigger threshold must be based on the data of the illuminance suitability analysis, and the synergistic optimization of the lighting environment comfort and energy saving effect is achieved.

In view of the energy use rebound effect, scholars at home and abroad have overcame this phenomenon by means of ecological feedback and adjustment of human energy use behaviour. Although the effect is not ideal, the use of intelligent lighting system eliminates this phenomenon well. In addition, this study only considers the dominant cost and income items in the analysis of economic benefits based on the conservatism principle; however, LED is a cold light source, which will inevitably reduce the energy of refrigeration of the air conditioning in summer. If these factors are considered, then the benefits of lighting energy efficiency retrofitting will be highly considerably.

\section{CONCLUSION}

On the basis of the lighting energy efficiency retrofitting project of a university library, this study aims to address the problem in which people only pay attention to the energy saving rate, ignore the illuminance standard after the retrofitting, and only pursue the high standard of the design but ignore the economy feasibility. This paper establishes a feasible decision system based on illuminance suitability analysis to achieve the overall goal optimization of multiple factors and avoid the phenomenon of "only caring for one thing" in the retrofit scheme.

The results show that using illumination test to select energy-saving lamps can simultaneously meet the requirements of illuminance and power density target value. The intelligent lighting system based on illuminance test can improve energy efficiency, achieve a comfortable visual environment, and overcome the energy use rebound effect. Finally, the calculation of the dynamic investment payback period verifies the feasibility of the retrofit scheme. The results not only apply to the lighting energy efficiency retrofitting of the library but also provide some reference value for energy efficiency retrofitting of other public buildings.

\section{ACKNOWLEDGEMENTS}

The authors are grateful for the support provided by the special scientific research founda- 
tion of doctorate in colleges and universities (No. 20116120110010), the soft science research project of the ministry of housing and urban-rural development (No. 2015-R1-010).

\section{REFERENCES}

1. Nan L, Zheng Y, Becerik-Gerber B, Chao T, Nanlin C. Why is the reliability of building simulation limited as a tool for evaluating energy conservation measures? Applied Energy, 2015. V159, \#12, pp.196-205.

2. Xin Z, Da Y, Tianzhen H, Xiaoxin R. Data analysis and stochastic modeling of lighting energy use in large office buildings in China. Energy and Buildings, 2015. V86, \#1, pp.275-287.

3. Marie-Claude D, Åke B. Energy saving potential and strategies for electric lighting in future North European, low energy office buildings: A literature review. Energy and Buildings, 2011. V43, \#10, pp. 2572-2582.

4. Guofeng M, Jing L, Nan L, Junjie Zhou. Cross-cultural assessment of the effectiveness of eco-feedback in building energy conservation. Energy and Buildings, 2017. V134, \#1, pp. 329-338.

5. Selcuk A, Nazmi E. Development of an outdoor lighting control system using expert system. Energy and Buildings, 2016. V130, \#10, pp.773-786.

6. Lvan C, Vineetha K, Naing Win O, Jussi P. Design of an energy-saving controller for an intelligent LED lighting system. Energy and Buildings, 2016. V120, \#5, pp.1-9.

7. Diaz-Mendez S E, Torres-Rodríguez A A, Abatal M, Escalante Soberanis M A, Bassam A. Economic, environmental and health co-benefits of the use of advanced control strategies for lighting in buildings of Mexico. Energy Policy, 2018. V113, \#2, pp.401-409.

8. Xuejun L. Application of teletraffic engineering modelling techniques for studying smart lighting systems for energy saving. Lighting Research and Technol, 2014. V46, \#2, pp.113-127.

9. Juan F. De Paz, Javier B, Sara R, Gabriel V, Juan M. Corchado. Intelligent system for lighting control in smart cities. Information Sciences, 2016. V372, \#12, pp.241-255.

10. Chih-Ling H, Chichun H, Yubin Chen. Development of an energy-saving glass using two-dimensional periodic nano-structures. Energy and Buildings, 2015. V86, \#1197, pp. 589-594.

11. Heng W, Xianmin Z, Peng G. Double freeform surfaces lens design for LED uniform illumination with high distance-height ratio. Optics \& Laser Technology, 2015. V73, \#10, pp.166-172.
12. Danny H W Li, Angela C K Cheung, Stanley K H Chow, Eric W M Lee. Study of daylight data and lighting energy savings for atrium corridors with lighting dimming controls. Energy and Buildings, 2014. V72, \#4, pp. 457-464.

13. Palacios-García E J, Chen A, Santiago I, Bellido-Outeiriño F J, Flores-Arias J M. Stochastic model for lighting's electricity consumption in the residential sector. Impact of energy saving actions. Energy and Buildings, 2015. V89, \#2, pp.245-259.

14. Shengnan L, Jaap H, Cees M. The influence of color association strength and consistency on ease of processing of ambient lighting feedback. Journal of Environmental Psychology, 2016. V47, \#9, pp.204-212.

15. Victor L. Chen, Magali A. Delmas, William J. Kaiser. Real-time, appliance-level electricity use feedback system: How to engage users? Energy and Buildings, 2014. V70, \#2, pp. 455-462.

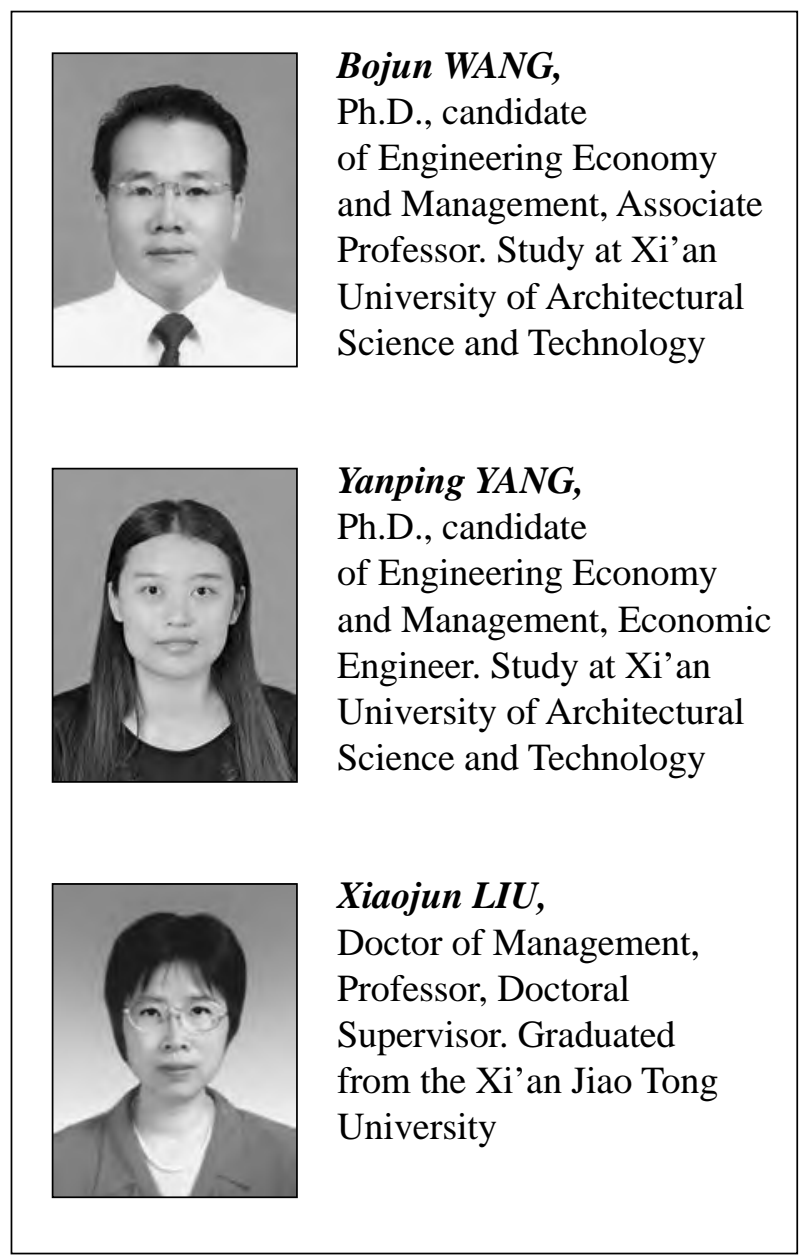

